\title{
Análise de causalidade da mortalidade das pequenas empresas no Brasil
}

\section{Causality analysis of the mortality of small businesses in Brazil}

\author{
Paulo Matos ${ }^{1}$ \\ Ary Vasconcelos ${ }^{2}$
}

\section{Resumo}

O propósito deste trabalho é fazer uma análise de causalidade da mortalidade das pequenas empresas no Brasil, baseada em situações conjunturais pré e pósimplantação do plano real no ano de 1994, no intervalo de 1985 a 2005. Para isso serão utilizados recursos econométricos que auxiliem a identificar características dos efeitos multiplicador, competitivo e de Marshall que impactam a extinção e abertura de empresas no mercado considerado, as inter-relações entre abertura e extinção, e vice-versa, para demonstrar o diagnóstico antes e depois deste plano econômico. Mais objetivamente, o trabalho consiste em medir e comparar o sentido dessas influências, pelo sinal marginal correspondente, expor as demonstrações descritivas e gráficas compatíveis, tendo como marco a implantação do real, deixando disponibilizados aos policy makers, tanto do segmento micro como macro, formas de analisar situações similares.

Palavras-chave: Análise de mortalidade. Pequenas empresas. Interrelações entre abertura e extinção. Efeito multiplicador. Efeito competitivo. Efeito de Marshall.

\section{Abstract}

the purpose of this study is to analyze the cause of mortality of small companies in Brazil, based on situations economics before and after real plan on 1994, on period between 1995 at 2005, using econometrics resources that aid to identify multiplier and competition characteristics of market, the interrelations between companies births and deaths, and the contrary, to show the diagnoses before and after real implantation. In truth, this study consists on the measure and compare the direction

\footnotetext{
Doutor em Economia pela EPGE/FGV-RJ e Professor Adjunto II da Pós-Graduação em Economia da Universidade Federal do Ceará (CAEN). Endereço de contato: Avenida da Universidade, $\mathrm{n}^{\circ} 2700,2^{\circ}$ andar, Bairro Benfica CEP 60020-181 Fortaleza- Ceará. Telefone: (55 85) 3366-7751. Emails: paulomatos@caen.ufc.br paulo.matos@fgv.br. Homepage: http://www. caen.ufc.br/ paulomatos

2 Mestre em Economia pela Pós-Graduação em Economia da Universidade Federal do Ceará (CAEN).
} 
of theses influences, by the corresponding sign of the marginal coefficient, the compatibles graphics demonstrations, considering the real implantation, with the aim, also, of let available to policy makers, of the micro and macro segments, forms of analyze alike situations.

Keywords: Mortality analisis. Small companies. Interrelations between births and deaths of companies. Multiplier characteristics. Competition characteristics. Marshall effect.

\section{Introdução}

As empresas de um modo geral, no mundo capitalista, e hoje no mundo globalizado, têm uma importância vital para a estabilidade da economia, considerando não apenas a produção e serviços disponibilizados a uma demanda cada vez mais insaciável, mas também as oportunidades de emprego, fonte dos recursos que sustentam essa demanda.

No Brasil, como em outros países de economias em desenvolvimento e desenvolvidos, um segmento importante desse conjunto de empresas é o que corresponde às pequenas empresas, que compõem uma parcela real e importante do mercado interno, devendo, portanto, serem alvos de atenção e mesmo de políticas públicas que as estimulem e preservem, alongando sua permanência no mercado.

Ressalte-se também a relevância desse segmento empresarial para a economia nacional, por constatar-se ser o maior empregador e, desse modo, formador da mão-de-obra, que sustenta a economia interna e, por isso mesmo, merecedor de todo cuidado por parte de todos aqueles que se interessem em alavancar a economia brasileira.

Como assinala Almeida (2009) "A propósito, ao contrário do que possa parecer, não são as grandes empresas as que, entre nós, mantêm maior contingente de empregados." Ao revés, são as microempresas e empresas de pequeno porte as responsáveis pela contratação de número expressivo de obreiros, merecendo, por isso mesmo, especial atenção do Estado, como deixa claro o art. 179 da Constituição Federal: 
"A União, os Estados, o Distrito Federal e os Municípios dispensarão às microempresas e às empresas de pequeno porte, assim definidas em lei, tratamento jurídico diferenciado, visando a incentiválas pela simplificação de suas obrigações administrativas, tributárias, previdenciárias e creditícias, ou pela eliminação ou redução destas por meio de lei".

Foi para atender a esta reconhecida relevância que já nos idos de 1984 surgiu no ordenamento jurídico nacional o primeiro instituto tido como o Estatuto da Microempresa, através da Lei 7.256, de novembro de 1984.

A constituição de 1988 deu às micro e pequenas empresas o status de valor prestigiado pela ordem econômica brasileira, de acordo com o inciso IX do art. 170 do Texto Constitucional, com o reforço do art. 179 já acima referenciado. Um segundo estatuto foi estabelecido pela Lei n 8.864 e neste foram promovidos alguns facilitadores em nível de caracterização das microempresas de acordo com o faturamento bruto e a simplificação da escrituração e dispensa de algumas obrigações trabalhistas.

Uma grande simplificação na tributação das Microempresas e Empresas de Pequeno Porte surgiu com a Lei 9.317, de 5 de dezembro de 1996, com a criação do chamado Simples.

Mais recentemente, o estatuto das Microempresas e da Empresa de Pequeno Porte com o suporte dos institutos legais Lei Complementar n. 123/2006 e Lei Complementar 127/2007, vem proporcionando a simplificação no cálculo e no recolhimento de tributos e nas relações de direito das microempresas com seus empregados.

O que se registra acima são estruturas jurídicas que proporcionam o surgimento de políticas públicas que se destinam a preservar este segmento empresarial merecedor desses cuidados pelo retorno que dá à economia nacional e teoricamente enquadram-se dentro do conceito do segundo teorema do bem-estar em busca da eqüidade, amenizando a ação nociva dos monopólios: "Qualquer alocação de 
bens e insumos eficiente em termos econômicos pode ser atingida como um equilíbrio geral competitivo por meio de uma alocação judiciosa da oferta de recursos escassos da economia", conforme registra Besanko \& Braeutigam (2004).

Esta é uma instância da responsabilidade do Estado, que, por outro lado, deve ser complementada com atitudes de gestão, da responsabilidade dos empresários ou executivos dessas empresas, para que se reflita na eficiência do ambiente econômico nacional, ajustandose ao que preceitua o primeiro teorema do bem-estar: "A alocação de bens e insumos que resulta de um equilíbrio geral competitivo é eficiente em termos econômicos. Isto é, dados os recursos disponíveis na economia, não existe outra alocação factível de bens e insumos que poderia melhorar simultaneamente todos os consumidores", relatado por Besanko \& Braeutigam (2004).

Ao realizar-se este trabalho, que levará em conta as quantidades de empresas constituídas e extintas no período de 1985 a 2005, a partir de informações das juntas comerciais, fica implícito que estaremos lidando essencialmente com as pequenas empresas, dado que correspondem à grande maioria no cenário nacional e buscará ao final resposta para as seguintes perguntas para cada segmento de período estudado: Constituição afeta constituição? Extinção afeta extinção? Constituição afeta extinção? Extinção afeta constituição?

O sentido desses resultados, representado pelos sinais dos coeficientes das regressões que serão trabalhadas, preencherão a matriz de visualização dos coeficientes que identificam as relações de efeitos multiplicador, competitivo e de ciclo de vida (Marshall), sugerida no artigo de The Interrelationships Between Births and Deaths, de Peter Johnson e Simon Parker). Estes resultados devem ser acompanhados de contextualizações relacionadas às motivações econômicas que justificam as respostas acima.

Dessa forma, a partir dos resultados encontrados na pesquisa, pode-se ter uma visão de conformidade desses resultados com as conjunturas econômicas de cada período, o que certamente ajudará a 
compreender a dinâmica e a natureza das inter-relações e causalidades das variáveis estudadas diante dos cenários econômicos pré-existentes.

Porque o processo competitivo no período Pré-Plano Real ficou circunscrito à extinção afetando extinção negativamente? Porque o período Pós-Plano real teve ampliado o leque de inter-relações entre constituições e extinções de empresas?

São perguntas pertinentes, surgidas no desenvolvimento deste trabalho, que nortearão a análise até sua conclusão.

Este trabalho encontra-se estruturado de forma que na próxima seção aborda-se a questão da literatura relacionada. Na seção 3, tem-se uma descrição da Metodologia econométrica, sendo destinadas às duas últimas seções á análise dos resultados e conclusão.

\section{Literatura relacionada}

\subsection{Literatura geral}

As empresas têm a atribuição de organizar sistemàticamente os fatores de produção para produzir bens ou prestar serviços. A este respeito relata Almeida (2009) que se atribui a Jean-Baptiste Say a definição de empresário como o "organizador da unidade econômica do regime capitalista, cabendo-Ihe combinar os fatores da produção sob sua responsabilidade e risco".

O nível de emprego ou desemprego é conseqüência da estabilidade ou instabilidade da conjuntura econômica vigente e pode demandar estruturas legais que viabilizem políticas públicas que favoreçam as pequenas empresas, a exemplo do Estatuto Nacional da Microempresa e da Empresa de Pequeno Porte (Lei Complementar n. 123, de 14.12.2006, alterada pela Lei Complementar n. 127, de 14.08.2007).

Como registra Moura (1998) "Hoje em dia, devido às transformações em curso, cada vez mais a indústria deixa de ser a grande geradora de empregos. Houve época em que ela era, sozinha, responsável por cerca de $25 \%$ dos empregos existentes...A grande dúvida atual é saber se as 
novas tecnologias serão capazes de gerar empregos que independam do chão da fábrica."

A mais recente e alentada pesquisa que levanta as causas da sobrevivência e mortalidade das pequenas empresas no Brasil foi realizada em 2007 pelo Instituto VOX POPULI, por encomenda do SEBRAE, que, de uma forma sintética, leva a atribuir-se a dois fatores o aumento da taxa de sobrevivência e a conseqüente diminuição da taxa de mortalidade: a maior qualidade empresarial e a melhoria do ambiente econômico.

Relata-se no sumário executivo dessa pesquisa que: "A redução e o controle da inflação, a gradativa diminuição das taxas de juros, o aumento do crédito para pessoas físicas e o aumento do consumo, especialmente das classes $\mathrm{C}, \mathrm{D}$ e $\mathrm{E}$, proporcionou um período favorável ao desenvolvimento dos pequenos negócios no Brasil".

Como metodologia compatível para desenvolver este trabalho do ponto de vista do embasamento econômico, aborda-se a seguir as situações conjunturais anterior e posterior ao plano real, com o objetivo de aliar as características de cada fase às conseqüências e fatos ocorridos em relação à extinção e abertura de empresas.

\subsection{Literatura específica}

Em recente trabalho, Rocco (2008), empenha-se em estabelecer as relações de causalidade entre constituição e extinção de empresas e o faz através de um modelo de vetores auto-regressivos e teste de causalidade. É um estudo investigativo da inter-relação dinâmica entre a constituição e extinção de firmas no Brasil entre janeiro de 1985 a dezembro de 2007.

Enquanto afinidade metodológica e de objetivo, sob o ponto de vista da auto-regressão, este é um trabalho referencial na medida em que aborda as técnicas de uma forma gradativa e interativa e culmina com a inferência dos resultados em uma contextualização econômica pertinente, para o período estudado. 
Outro trabalho de referência, este relacionado ao arcabouço metodológico, é o de Matos e Lemos (2009), pela abrangência das vertentes metodológicas de natureza auto-regressiva, do qual se pode usar como benchmark em trabalhos com utilização do VAR.

Um trabalho a ser seguido como padrão nesta pesquisa tratase de The Interrelationships Between Births and Deaths, de Peter Johnson e Simon Parker, do qual se utiliza principalmente a tabela correspondente ao sumário de efeitos de causalidade entre as variáveis estudadas, no qual se aplicam os sinais desses efeitos.

É pertinente registrar-se a leitura necessária das obras literárias especializadas em econometria listadas na referência bibliográfica deste trabalho.

\section{Breve histórico sobre a economia brasileira}

Neste item aborda-se, sob o ponto de vista da conjuntura macroeconômica, os dois períodos relevantes desta pesquisa, o período Pré-Plano Real, que vai de janeiro de 1985 a fevereiro de 1994 , e período Pós-Plano Real, que vai de março de 1994 a dezembro de 2005.

\subsection{Período Pré-Plano Real}

Uma parte do período pré-real é a chamada década perdida (1980), onde três ocorrências marcantes influíram forte e negativamente na economia nacional. A primeira delas foi o segundo choque do petróleo, no qual o preço atingiu a US\$ 30 por barril em 1979 (estava em torno de US\$12,5 em 1973), forçando o país a reduzir drasticamente as importações, aumentar a produção interna e a estimular a produção do álcool.

A segunda ocorrência que prejudicou o país nessa década foi o aumento das taxas de juros internacionais no período de 1981 a 1985, implicando em um grande incremento nas remessas de juros decorrentes da dívida externa e evidentemente provocando inapetência aos aplicadores externos na economia nacional. 
E finalmente, a terceira ocorrência negativa representada pela queda nos preços das commodities no período de 1981 a 1985, resultando em uma grande perda de divisas.

Isso tudo levou o país a uma degradação na sua economia, com ocorrência de recessão, desemprego, aumento da dívida externa, inflação e queda da renda per capita. (Mendes, Judas Tadeu Grassi, 2005).

$\mathrm{Na}$ década de 90 grandes mudanças ocorreram no sentido de adequar a economia nacional ao processo de globalização que assomava a economia mundial, sendo a abertura da economia o carro chefe dessas mudanças.

Até então a economia brasileira era muito fechada e isso provocava uma limitação muito grande nas importações, dando como conseqüência um saldo relativamente expressivo da balança comercial, o que levava a uma falsa impressão de ser um atributo importante, mas na realidade isso ocorria por que qualquer nível de exportação tornava-se superior à importação dado o nível mínimo desta.

Essa limitação reprimia o desenvolvimento brasileiro, não só pela falta de concorrência, como pela incapacidade de produzir bens de capital de alta tecnologia, característica dos países que ainda não galgaram alto nível de desenvolvimento. Três procedimentos levavam a economia a ser assim reprimida: alíquotas de importação elevadas, restrição de importação de determinados produtos pela alegada necessidade de proteger a indústria nacional e por fim a recessão interna associada ao surrado programa de substituição de importações.

A abertura da economia brasileira que se iniciou no começo da década de 90, através de redução nas alíquotas de importação, fez com que houvesse paulatinamente um acirramento da concorrência beneficiando diretamente os consumidores, tendo esses reflexos aparecido mais fortemente a partir de 1997.

Esse benefício decorre de um ambiente competitivo, que obriga às empresas a terem atenção com: maior produtividade, menor custo unitário e melhor qualidade. 


\subsection{Período Pós-Plano Real}

O plano real foi conduzido na prática sob duas óticas, uma combinando uma âncora cambial (devido à folga cambial pelo grande fluxo de recursos dado o excesso de liquidez internacional) com crescimento econômico; e outra, uma âncora monetária com diminuição das taxas de crescimento e aumento das taxas de desemprego. A primeira fase foi até o início de 1995, após a crise do México, e após isso foram criadas as bandas cambiais. (Sandroni, Paulo, 2005)

A partir daí passou-se a dar ênfase à âncora monetária, com medidas para contenção da demanda, via restrição de crédito, elevação da taxa de juros e gradual alteração na política cambial. As crises cambiais da Ásia e da Rússia, em 1997 e 1998, respectivamente, obrigaram o Governo a elevar a atenção para políticas monetárias restritivas, com os conseqüentes aumentos da recessão e desemprego.

A partir de 1999, após a crise da Rússia, a taxa de câmbio voltou a flutuar livremente, foi estabelecido o sistema de metas de inflação, e a taxa de juros deixou de ser instrumento de balizamento da taxa de câmbio.

Até 2003 a taxa de câmbio passava por uma desvalorização de mais de $140 \%$, favorecendo as importações, e somente não chegando a ser prejudicial às exportações em face do alto preço das commodities no mercado internacional.

\section{Metodologia da abordagem empírica}

A abordagem empírica deste trabalho é feita com a utilização do modelo conhecido como auto-regressões vetoriais (VAR), um dos modelos aplicáveis em séries temporais, que na sua introdução através de um trabalho de Sims mostrou-se ser uma alternativa aos modelos dinâmicos de equações estruturais.

O teste de causalidade de Granger é considerado a semente deste modelo, Gurjarati (2005), e através dele pode-se saber, considerando- 
se as variáveis $\mathrm{Y}$ e $\mathrm{X}$, quem causa quem, podendo ocorrer uma das seguintes situações: causalidade unidirecional de $X$ para $Y$, unidirecional inversamente de $Y$ para $X$, causalidade bilateral ou realimentação, quando há causalidade nos dois sentidos de $X$ para $Y$ e de $Y$ para $X$ e, finalmente, independente, quando os coeficientes de ambas as regressões não são estatisticamente significativos.

Há um roteiro simples para o cálculo desse teste, que consiste nos seguintes passos:

1 - Regredir o Y sobre todos os $Y$ defasados, e outras variáveis, se houver, mas não incluir as variáveis defasadas de $X$ nessa regressão. Esta é a regressão restrita, e dela obtém-se a soma dos quadrados dos resíduos restrita, SQRr.

2 - Roda-se a regressão incluindo os termos defasados de $X$. Essa é a regressão irrestrita. Dessa regressão obtém-se a soma dos quadrados dos resíduos irrestrita, SQRir;

3 - A hipótese nula é Ho: $\sum \alpha i=0$, que é a hipótese de termos defasados de $\mathrm{X}$ não pertence à regressão;

4 - Para testar esta hipótese aplica-se o teste $\mathrm{F}$ requerido para este roteiro (Gujarati, 2005).

Dessa forma antes de definir as equações para o processo de autoregressão no modelo VAR já se pode ter uma idéia da significância dos coeficientes dessas equações se for procedido o teste de causalidade de Granger.

O VAR é um modelo ateórico, ou seja, prescinde de estar atrelado a uma teoria econômica para a sua formulação e, em princípio, todas as variáveis do modelo são endógenas, interagindo entre elas.

Em sua estrutura, na forma purista, o VAR, formulado por Sims, pela própria raiz de sua denominação "auto-regressões" tem como variáveis independentes as próprias variáveis dependentes defasadas. Se em cada equação não há variáveis endógenas não defasadas do lado direito e as variáveis independentes são as mesmas, o estimador 
por Mínimos Quadrados Ordinários é consistente e eficiente. (Pindyck, 2004).

De forma mais geral o modelo VAR pode ser trabalhado com aplicação dos Mínimos Quadrados Ordinários, ou seus variantes, conforme peculiaridades ou violações das séries a determinadas hipóteses básicas da regressão linear, e em que as variáveis do lado direito não serão necessàriamente correspondentes às variáveis dependentes que são regredidas no modelo, podendo ser as defasagens de mesma ordem ou não.

Rocco (2008) faz referência a um processo, de acordo com Holtz et al (1989), que consta de três passos:

i) Estimar por mínimos quadrados de 2 estágios (MQ2E) para cada período de tempo;

ii) Estimar a covariância conjunta dos termos de erro usando os resíduos e a matriz de instrumentos;

iii) Estimar todos os parâmetros simultaneamente usando mínimos quadrados generalizados.

São exigências do modelo VAR: a estacionariedade das séries temporais e a não existência de autocorrelação nos erros.

A estacionariedade pode ser identificada visualmente nos correlogramas FAC e FACP ou nos gráficos das próprias variáveis dispostas ao longo do tempo, podendo também e principalmente ser identificada através do teste ADF.

Há alguns critérios para a definição da quantidade de defasagens (lags) a serem aplicadas nas variáveis independentes, tais como o que leva em conta o $\mathrm{R}^{2}$ corrigido, a informação de Akaike e o critério de Schwartz, todos eles associados com o bom senso do pesquisador dado que nenhum tem uma resposta definitiva e clara.

Um modelo VAR com duas variáveis dependentes poderia ser representado através da seguinte expressão, a qual é uma representação básica por não conter variáveis exógenas: 


$$
\left\{\begin{array}{l}
\Delta \text { Const }_{t}=\rho_{c}+\sum_{i=1}^{2} \rho_{c c}(i) \Delta \text { Const }_{t-i}+\sum_{i=1}^{2} \rho_{c e}(i) \cdot \Delta \text { Ext }_{t-i}+\mathrm{v}_{c t} \\
\Delta E X t_{t}=\rho_{e}+\sum_{i=1}^{2} \rho_{e c}(i) \Delta \text { Const }_{t-i}+\sum_{i=1}^{2} \rho_{e e}(i) . \Delta \text { Ext }_{t-i}+\mathrm{v}_{e t}
\end{array}\right.
$$

Como exemplificação, e já sintonizando com o objeto deste trabalho, $\Delta$ Const consiste na variação da variável correspondente a constituição de empresas, em um determinado período, e $\Delta$ Ext consiste na variação da quantidade de empresas extintas neste mesmo período. O modelo trata estas variáveis em relação a elas mesmas, a valores defasados e intercambiadas, tais como Const depende de Ext, e viceversa, também de forma defasada, tudo em uma dimensão dinâmica.

Sem negligenciar as sinalizações dos testes econométricos, mas aliando a isto o bom-senso sugerido ao largo da bibliografia pertinente, utiliza-se neste trabalho uma definição de 2 defasagens para as variáveis do lado direito de cada equação.

Por outro lado, como já assinalado, dado que as variáveis independentes são as mesmas para todas as equações neste trabalho, o método dos Mínimos Quadrados Ordinários pode ser utilizado por ser consistente e eficiente neste caso.

\section{Análise dos resultados}

\subsection{Base de dados e estatísticas descritivas}

Os dados trabalhados nesta pesquisa estão contidos nos arquivos varprereal.xls e varposreal.xls, e compreendem, respectivamente, as quantidades de constituições e extinções mensais, nos períodos janeiro de 1985 a fevereiro de 1994, e março de 1994 a dezembro de 2005, dos quais foram extraídos aspectos importantes a seguir relatados.

Registre-se, de antemão, que todas as tabelas e gráficos que serão referidas neste item estão posicionados no Apêndice ao final deste trabalho.

Inicialmente demonstra-se através de um comparativo de estatísticas descritivas, entre o pré e o pós-real, o comportamento das 
variáveis Const $=$ constituições e Ext $=$ extinções, podendo-se já a partir dessa demonstração iniciar-se um processo de entendimento que formará ao final a convicção sobre o comportamento dessas duas séries, nos dois períodos.

Nas Tabelas 1 e 2, pode-se perceber as estatísticas descritivas de constituições e extinções de empresas, não só abrangendo em um intervalo único os dois períodos, como está na tabela 1, mas também de uma forma relacionado onde se procura investigar já a partir desses dados a evolução/involução entre os períodos

Ao verificar-se a coluna de variações percentuais da tabela acima, dois pontos ficam bem evidentes: o primeiro é a expressiva variação percentual da média mensal de extinções, na ordem de $69,68 \%$, do período pré para o pós-real, contra apenas $8,38 \%$ de aberturas; e o segundo ponto é a maior ainda variação do desvio padrão de extinções de um período para o outro, da ordem de 137,48 \%, contra uma variação negativa do desvio padrão de aberturas, da ordem de $-37,11 \%$.

A abordagem inferencial, sob o modelo VAR, requereu alguns procedimentos preliminares, nos quais já se delineiam alguns posicionamentos dessas variáveis posteriormente constatados

Estes procedimentos investigaram a dependência entre as variáveis, através do teste de causalidade de Granger referenciado no item anterior, e a estacionariedade, como se aborda a seguir.

Procedendo-se o teste de causalidade de Granger já se constata a fraca dependência entre as variáveis $\Delta$ Const e $\Delta E x t$, e vice-versa, no período pré-real, o que se reflete nos resultados das equações regredidas. Já no período pós-real, a dependência recíproca é ressaltada, o que também é refletida nas suas regressões.

A estacionariedade é primeiramente visualizada de forma superficial nos gráficos das Figuras 1 e 2 e principalmente assegurada com as diferenciações (1 diferença para cada equação), atestada com a aplicação no teste de raiz unitária Augumented Dickey-Fuller, ADF, à exceção da variável Ext para a qual se pode rejeitar a hipótese nula de presença de raiz unitária na série, constante da Tabela 3. 


\subsection{Resultados e discussões}

Após a posição dos resultados estatísticos descritivos anteriormente expostos, a referência sobre o teste de causalidade de Granger, e um enfoque sobre estacionariedade, como pré-requisito das séries temporais para desenvolver-se um trabalho com o modelo VAR, todos devidamente visualizados via gráficos e tabela, chega-se ao estágio da pesquisa no qual surgirão as influências auto-regressivas das variáveis trabalhadas. Estes resultados serão sintetizados ao preencherse a tabela sugerida por Peter Johnson e Simon Parker, no paper The Interelationships Between Births and Deaths.

A pesquisa desses autores, de 1993, usando o modelo VAR, encontrou efeito competitivo para a equação de constituição e efeito multiplicador para a equação de extinção.

O trabalho de Rocco (2008) constatou que no período inflacionário, entre 1985 e 1994 constituições de empresas levaram a extinções, e sugeriu ser decorrente do aumento da concorrência com firmas mais eficientes, conseqüente baixa no lucro de firmas antigas que não se adaptam ao surgimento das novas e dificuldades financeiras encontradas no ambiente econômico. Para o mesmo período o resultado foi de que extinções não causam novas constituições.

O mesmo autor encontra para o período 1995 e 2007 a situação em que constituição causa extinção e vice-versa.

Registre-se que Rocco trabalha com períodos divergentes dos períodos alcançados por esta pesquisa.

A partir deste ponto serão trabalhados os resultados econométricos para a conexão com a conjuntura macroeconômica nos períodos pré e pós-real, viabilizando os argumentos necessários para a conclusão do trabalho, que tem a incumbência de proporcionar a intelegibilidade da interação entre o que resulta dos números e as conjunturas econômicas referidas. Visa-se com isso robustecer esses resultados, tendo em vista que a formulação do modelo prescindiu de uma teoria econômica que o embasasse. 
Os coeficientes das equações do VAR foram encontrados a partir da auto-regressão das equações diferenciadas, e originárias de um modelo vetorial tipo (1), com definição de 2 lags para ambas as equações, em cada período, definidos a partir do critério de Shwarz, conforme se demonstra nas Tabelas 4 e 5.

Na Figura 3, visualiza-se o comportamento em resposta a um choque nas variáveis dependentes administrado a uma ou mais equações no sistema, percebendo-se a confluência a partir de algum tempo, o que no dizer de Matos e Lemos, (2009) significa que "os choques se dissipam sem gerar efeitos permanentes, uma característica necessária para que a modelagem de correção de erros seja adequadamente especificada e estimada".

Os sinais dos coeficientes, produtos das regressões dessas equações, deram elementos para a formatação da Tabela 6, que representa uma matriz característica da idealização dos autores Peter Johnson e Simon Parker no artigo The Interrealationships Between Births and Deaths.

Os efeitos marginais encontrados através das equações que produziram os coeficientes e parâmetros constantes das Tabelas 4 e 5, utilizando o modelo VAR com dois lags, levaram aos resultados que indicam: 1 - no período pré-real, extinção afeta extinção negativamente; 2 - no período pós-real, constituição afeta constituição negativamente, extinção afeta constituição negativamente e constituição afeta extinção negativamente. São resultados trazidos unicamente pelos números, mas que devem ser reflexos de conjunturas macroeconômicas a seguir abordadas na conclusão deste trabalho.

\section{Conclusão}

Esta análise considerou o cotejamento de duas séries temporais de mesma natureza, mas de sentidos contrários, constituição e extinção de empresas, e teve o objetivo de encontrar nos dois períodos estudados, pré e pós-real, no intervalo de 1985 a 2005, as relações autorregressivas 
entre essas variáveis, utilizando o modelo VAR, um modelo alternativo aos estruturais e dinâmicos. .

Procurou-se encontrar as inter-relações que captassem os efeitos multiplicadores, concorrenciais e de Marshall, no sentido de Peter Johnson e Simon Parker, no artigo The Interrelationships Between Births and Deaths, e encontradas as estimativas dessas interrelações, conectá-las com as situações conjunturais macroeconômicas, nos respectivos períodos, dado que, embora ao estruturar o modelo não houvesse uma base de teoria econômica na sua formulação, os resultados dos números devem ser entendidos como conseqüências desses cenários.

Assimé que, o efeito encontrado, relativamente ao período pré-real, é consentâneo com um cenário econômico difícil, como o da década de 80 , chamada década perdida, e início de 90 , pois expressa um processo auto-regressivo de extinção provocando extinção negativamente, um processo competitivo portanto circunscrito a extinções, que reflete instabilidade na medida em que decorre de falta de oportunidades característico de um ambiente em processo de incertezas, marcado com recessão, queda da renda, inflação, desemprego e aumento significativo da dívida externa

No período pós-real, os efeitos são mais abrangentes e compreendem, por um lado, os processos auto-regressivos competitivos tais como: constituições afetando constituições negativamente, extinções afetando extinções negativamente; e, por outro lado, os processos auto-regressivos multiplicativos, caracterizados por extinções afetando constituições negativamente, constituições afetando extinções negativamente, tudo isso dentro do ambiente econômico prevalecente, tendente a uma ampla abertura, estabilização da moeda, e captando os malefícios e benefícios da globalização, originados do obsoletismo e de inovações tecnológicas, uma característica desse período. 


\section{Referência}

BESANKO, David; BRAEUTIGAM, Ronald R. Microeconomia: uma abordagem completa. Rio de Janeiro: LTC, 2004.

GUJARATI, D. Economia básica. São Paulo: Makron, 2000.

JOHNSON, P.; PARKER, S. The interrelationships between births and deaths. Small Business Economics, Netherlands, v. 6, n. 4, p. 283-290, Ago. 1994.

KENNEDY, Peter. Manual de econometria. Rio de Janeiro: Elsevier, 2009.

MATOS, Paulo R. Faustino; COSTA, João H. Lemos. Análise do impacto da classificação de risco no mercado de crédito brasileiro. Planejamento e Políticas Públicas, Fortaleza, v. 2, p. 67-92, 2009.

MENDES, Judas Tadeu Grassi. Economia: fundamentos e aplicações. Pearson, São Paulo: Pearson, 2004.

MOURA, Paulo C. A crise do emprego: uma visão além da economia. 4. ed. Rio de Janeiro: Mauad, 1998.

PINDYCK, Robert; RUBINFELD, Daniel. Econometria: modelos \& previsões. Rio de Janeiro: Elsevier, 2004.

ROCCO, Leandro de Almeida. Inter-relação entre constituição e extinção de firmas no Brasil. 2008. 214 f. Dissertação (Mestrado em Economia)Programa de Pós-Graduação em Economia, Universidade Federal do Ceará, Fortaleza, 2008.

SANTOS, Cairon Ribeiro Dos; ALMEIDA, Amador Paes De; CORTEZ, Julpiano Chaves. Comentários ao estatuto da microempresa e da empresa de pequeno porte. São Paulo: Saraiva, 2009.

SARTORIS, Alexandre. Estatística e introdução à econometria. São Paulo: Saraiva, 2003.

SEBRAE. Fatores condicionantes e taxas de sobrevivência e mortalidade das micro e pequenas empresas no Brasil no ano de 2003-2005. Brasília, 2007. 


\section{APÊNDICE - Tabelas e Gráficos.}

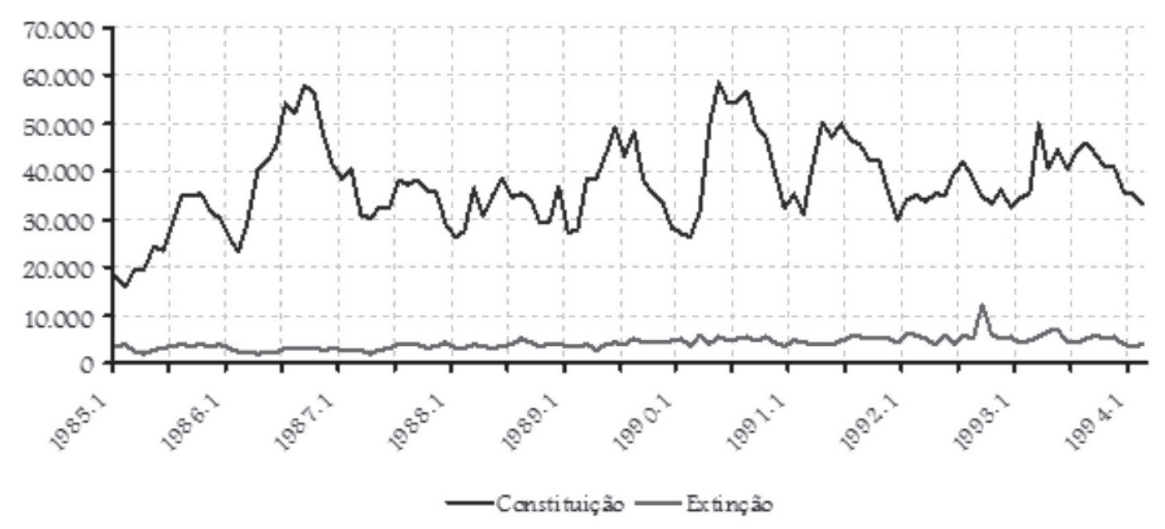

Figura 1: Constituição e Extinção de Empresas no Brasil (Pré-Plano Real, 1985 - fevereiro de 1994)

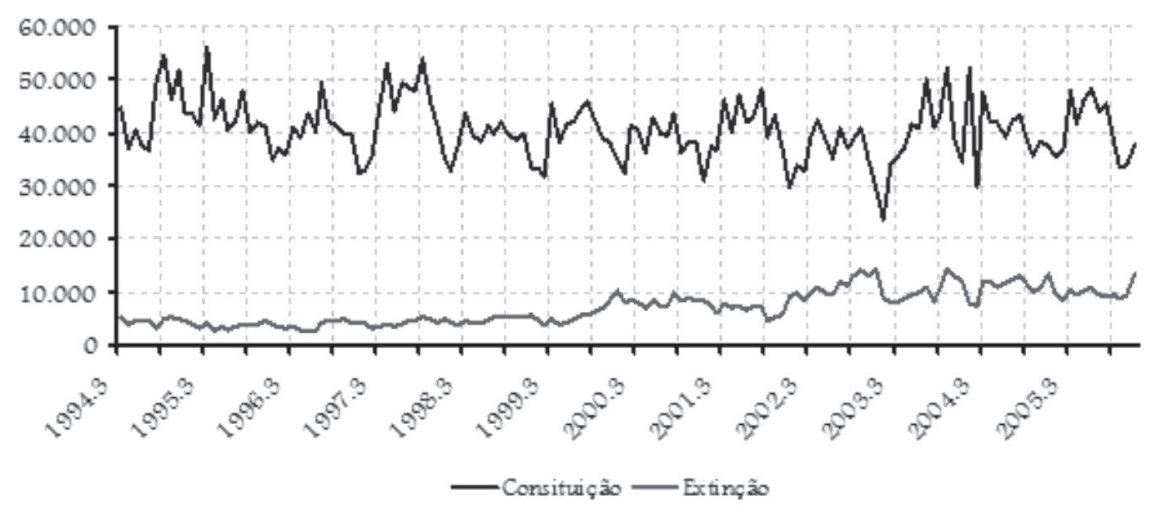

Figura 2: Constituição e Extinção de Empresas no Brasil (Pré-Plano Real, março de 1994 - 2005) 
Tabela 1: Estatística descritiva da série de constituição de empresas ao Brasil (período: janeiro de 1985 a dezembro de 2005, 252 observações)

\begin{tabular}{lrrrr}
\hline \multicolumn{5}{c}{ Constituição } \\
& \multicolumn{1}{c}{ Média } & $\begin{array}{l}\text { Desvio } \\
\text { Padrão }\end{array}$ & Mínimo & Máximo \\
\cline { 2 - 5 } Período: & 39.264 & 7.335 & 16.059 & 58.415 \\
Completo: janeiro 1985 - dezembro 2005 & & & & \\
Pré-Plano Real: janeiro 1985 - fevereiro 1994 & 37.492 & 8.846 & 16.059 & 58.415 \\
& & & & \\
Pós-Plano Real: março 1994 - dezembro 2005 & 40.636 & 5.563 & 23.522 & 56.043 \\
\hline
\end{tabular}

Tabela 2: Estatística descritiva da série de extinção de empresas ao Brasil (período: janeiro de 1985 a dezembro de 2005, 252 observações)

\begin{tabular}{|c|c|c|c|c|}
\hline \multicolumn{5}{|c|}{ Extinção } \\
\hline Período: & Média & $\begin{array}{l}\text { Desvio } \\
\text { Padrão }\end{array}$ & Mínimo & Máximo \\
\hline Completo: janeiro 1985 - dezembro 2005 & 5.815 & 2.903 & 1.875 & 14.487 \\
\hline Pré-Plano Real: janeiro 1985 - fevereiro 1994 & 4.176 & 1.326 & 1.875 & 12.176 \\
\hline Pós-Plano Real: março 1994 - dezembro 2005 & 7.086 & 3.149 & 2.811 & 14.487 \\
\hline
\end{tabular}

Fonte: Juntas comerciais 
Tabela 3: Ordem de integração das variáveis do modelo.

\section{Teste ADF de raiz unitária}

Variável

Cons

Ext

$\triangle$ Cons

$\Delta E x t$

\section{Estatística t}

$-7,4715$

$-1,9248 *$

$-5,8738$

$-12,5968$

\section{Prob}

0,0000

0,3205

0,0000

0,0000

Valores Críticos :

$$
\begin{array}{ll}
5 \%= & -2.8730 \\
1 \%= & -3.4566
\end{array}
$$

Notas: 1) Teste de raiz unitária Augmented Dickey-Fuller em nível com intercepto de 1985:01 a 2005:12. * Indica que não se pode rejeitar a hipótese nula de presença de raiz unitária na série.

Tabela 4: Estimativa do VAR no período Pré-Plano Real (1985:1 - 1994:2)

$$
\left\{\begin{array}{l}
\Delta \text { Const }_{t}=\rho_{c}+\sum_{i=1}^{2} \rho_{c c}(i) \Delta \text { Const }_{t-i}+\sum_{i=1}^{2} \rho_{c e}(i) \cdot \Delta E x t_{t-i}+v_{c t} \\
\Delta E X t_{t}=\rho_{e}+\sum_{i=1}^{2} \rho_{e c}(i) \Delta \text { Const }_{t-i}+\sum_{i=1}^{2} \rho_{e e}(i) \cdot \Delta E x t_{t-i}+v_{e t}
\end{array}\right.
$$

\begin{tabular}{|c|c|c|c|c|c|}
\hline \multicolumn{3}{|c|}{$\Delta$ Const } & \multicolumn{3}{|c|}{$\Delta E x t$} \\
\hline \multicolumn{2}{|c|}{ Coeficientes } & \multirow{2}{*}{$\begin{array}{r}\text { Erro padrão } \\
508,518\end{array}$} & \multicolumn{2}{|c|}{ Coeficientes } & \multirow{2}{*}{$\begin{array}{r}\text { Erro padrão } \\
104,522\end{array}$} \\
\hline$\rho_{c}$ & 108,694 & & $\rho_{e}$ & 5,852 & \\
\hline$\rho_{c c(1)}$ & 0,046 & 0,099 & $\rho_{e c(1)}$ & 0,013 & 0,099 \\
\hline$\rho_{c c(2)}$ & 0,082 & 0,099 & $\rho_{e c(2)}$ & $0,037 *$ & 0,099 \\
\hline$\rho_{c e(1)}$ & $-0,657$ & 0,467 & $\rho_{e e(1)}$ & $-0,544^{*}$ & 0,099 \\
\hline$\rho_{c e(2)}$ & $-0,378$ & 0,471 & $\rho_{e e(2)}$ & $-0,169^{*}$ & 0,099 \\
\hline \multicolumn{3}{|c|}{ Schwarz: 20,017} & \multicolumn{3}{|c|}{ Schwarz: 16,853} \\
\hline
\end{tabular}

(Período: 1985 :01 a 1994:02 - 107 observações )

Notas: 1) Estimação tradicional de VAR. 2) * Valor estatístico significativo ao nível de 5\%. 
Tabela 5: Estimativa do VAR no período Pós-Plano Real (1994:3 - 2005:12)

$$
\left\{\begin{array}{l}
\Delta \text { Const }_{t}=\rho_{c}+\sum_{i=1}^{2} \rho_{c c}(i) \Delta \text { Const }_{t-i}+\sum_{i=1}^{2} \rho_{c e}(i) \cdot \Delta E x t_{t-i}+v_{c t} \\
\Delta E X t_{t}=\rho_{e}+\sum_{i=1}^{2} \rho_{e c}(i) \Delta \text { Const }_{t-i}+\sum_{i=1}^{2} \rho_{e e}(i) \cdot \Delta E x t_{t-i}+v_{e t}
\end{array}\right.
$$

\begin{tabular}{|c|c|c|c|c|c|}
\hline \multicolumn{3}{|c|}{$\Delta$ Const } & \multicolumn{3}{|c|}{$\Delta E x t$} \\
\hline \multicolumn{2}{|c|}{ Coeficientes } & \multirow{2}{*}{$\begin{array}{c}\text { Erro padrão } \\
508,518\end{array}$} & \multicolumn{2}{|c|}{ Coeficientes } & Erro padrão \\
\hline$\rho_{c}$ & 95,290 & & $\rho_{e}$ & 84,581 & 104,522 \\
\hline$\rho_{c c(1)}$ & $-0,523 *$ & 0,084 & $\rho_{e c(1)}$ & $-0,040 *$ & 0,021 \\
\hline$\rho_{c c(2)}$ & $-0,074$ & 0,083 & $\rho_{e c(2)}$ & $0,034 *$ & 0,021 \\
\hline$\rho_{c e(1)}$ & $-0,643 *$ & 0,351 & $\rho_{e e(1)}$ & $-0,104$ & 0,087 \\
\hline$\rho_{c e(2)}$ & $-1,256^{*}$ & 0,354 & $\rho_{e e(2)}$ & $-0,370 *$ & 0,087 \\
\hline \multicolumn{3}{|c|}{ Schwarz: 20,103 } & \multicolumn{3}{|c|}{ Schwarz: 17,304} \\
\hline
\end{tabular}

(Período: 19 94:03 a 2005:12 - 142 observações )

Notas: 1) Estimação tradicional de VAR. 2) * Valor estatístico significativo ao nível de 5\%.

Tabela 6. Quadro sumário dos efeitos evidenciados

EFEITO

PRÉ-REAL:

PÓS-REAL

MARGINAL

Mult. Comp. Marshall

Mult. Comp. Marshall

$\overline{\delta C o n s t}_{\mathrm{t}} / \delta$ Const $_{\mathrm{t}-\mathrm{p}}$

$\delta \mathrm{Ext}_{\mathrm{t}} / \delta \mathrm{Ext}_{\mathrm{t}-\mathrm{p}}$

$\delta$ Const $_{\mathrm{t}} / \delta \mathrm{Ext}_{\mathrm{t}-\mathrm{p}}$

$\delta \mathrm{Ext}_{\mathrm{t}} / \mathrm{\delta Const}_{\mathrm{t}-\mathrm{p}}$ 

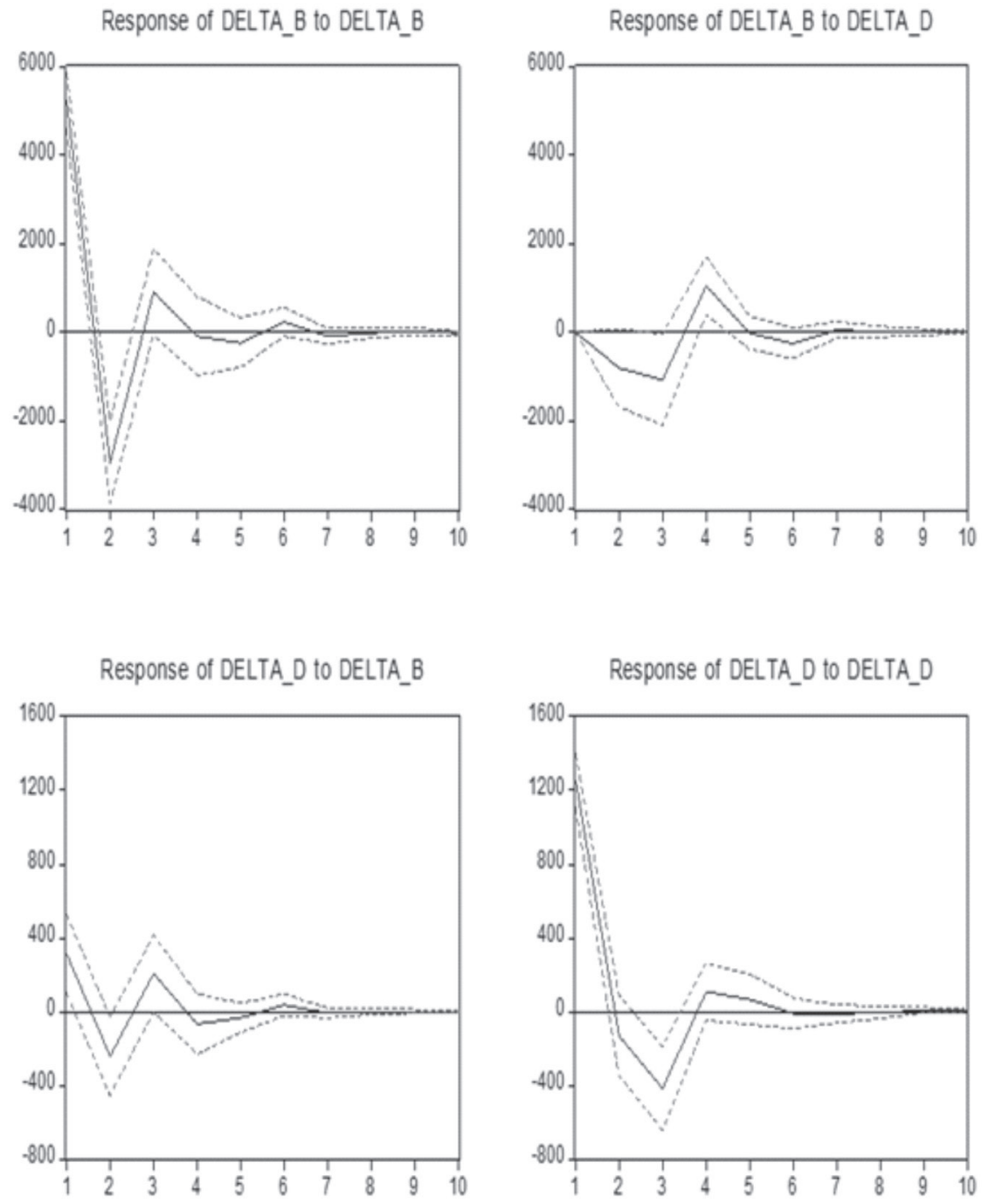

Figura 3: Impulso-resposta (Cholesky) do VAR.

Artigo Recebido em: 15/01/2013

Revisado em: 10/03/2013

Aprovado em: 17/04/2013 